
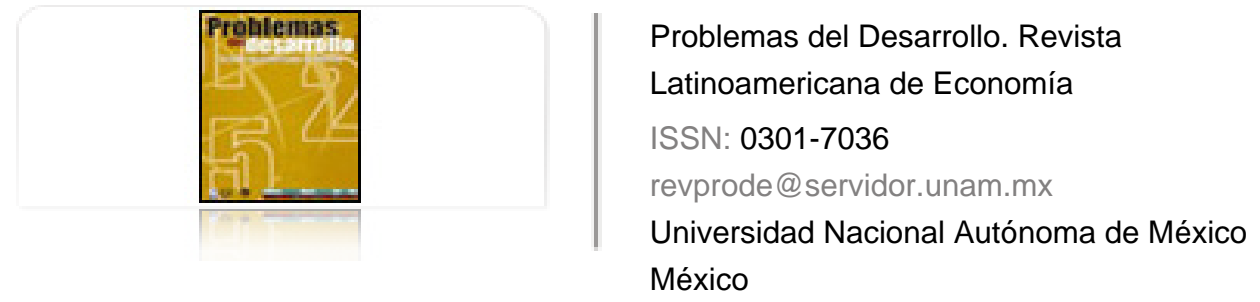

Merchand Rojas, Marco A.

Desarrollo inter-estatal turístico de Puerto Vallarta y Bahía de Banderas: México Problemas del Desarrollo. Revista Latinoamericana de Economía, vol. 43, núm. 168, enero-marzo, 2012, pp. 147-173

Universidad Nacional Autónoma de México

Distrito Federal, México

Disponible en: http://www.redalyc.org/articulo.oa?id=11822277007

Cómo citar el artículo

- Número completo

- Más información del artículo

Página de la revista en redalyc.org

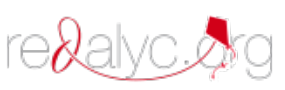

Sistema de Información Científica

Red de Revistas Científicas de América Latina, el Caribe, España y Portugal Proyecto académico sin fines de lucro, desarrollado bajo la iniciativa de acceso abierto 
Revista Problemas del Desarrollo, 168 (43), enero-marzo 2012

\title{
DESARROLLO INTER-ESTATAL TURÍSTICO DE Puerto Vallarta y Bahía de Banderas: MÉxico
}

\author{
Marco A. Merchand Rojas*
}

Fecha de recepción: 8 de febrero de 2011. Fecha de aceptación: 24 de agosto de 2011.

\section{RESUMEN}

El objetivo de este trabajo consiste en mostrar que la consolidación de los capitales ubicados en la región costera de ambos municipios, propicia una complementariedad y compatibilidad entre la economía de mercado (intereses micro empresariales exclusivos) y la política de ordenamiento territorial, ${ }^{1}$ creación de Centros Integralmente Planeados (CIP) que gesta el Estado para consolidar los capitales turísticos en la región. Es a través del acompańamiento entre los capitales extranjeros y las políticas territoriales impulsadas por el Estado que se sustenta la actividad turística y que tiene el prototipo de un enclave económico como son los Centros Integralmente Planeados que responden a una política de desarrollo turístico fomentado por el Estado Federal y local, apostando a que estos capitales generen "círculos virtuosos de desarrollo económico".

Palabras clave: Región, Estado, turismo, Puerto Vallarta.

\section{The inter-state development of Puerto Vallarta AND BAHÍA DE BANDERAS: MeXico}

Abstract

The aim of this study is to show that the consolidation of capital located in the coastal region of both municipalities promotes complementarity and compatibility between the market economy (exclusive micro-business interests) and the policy of territorial ordering (creation of Integrally Planned Centers -CIPs) which the State implements to consolidate tourism capital in the region. It is by associating foreign capital with territorial policies promoted by the State that tourism activity is sustained and takes the form of a prototype economic enclave, as the CIPs respond to a tourism development policy promoted by the federal and local states, in the expectation that these capitals will generate "virtuous circles of economic development".

Keywords: Region, State, tourism, Puerto Vallarta

* Profesor-investigador de la Universidad de Guadalajara. Correo electrónico: merchandrojas@ yahoo.com.mx

1 El ordenamiento territorial (от) se concibe como un proceso y una estrategia de planificación de carácter técnico-político con lo que se pretende configurar, en el largo plazo, una organización del uso y la ocupación del territorio, acorde con las potencialidades y limitaciones del mismo, las expectativas y aspiraciones de la población y los objetivos sectoriales de desarrollo (económicos, sociales, urbano-regionales y ecológicos). 
Marco A. Merchand Rojas

\section{LE DÉVELOPPEMENT DE PUERTO VALLARTA ET BAHÍA DE BANDERAS AU MEXIQUE \\ Résumé}

L'objectif de ce travail consiste à montrer que la consolidation du capital placé dans la région côtière de ces deux municipalités témoigne de la compatibilité et de la complémentarité qui peut exister entre l'économie de marché (intérêts des micro entreprises exclusivement) et la politique de planification territoriale (création de centres intégralement planifiés) que mène l'État pour renforcer le tourisme dans la région. C'est la combinaison de capitaux étrangers et des politiques territoriales mises en œuvre par l'État qui permettent l'activité touristique en faisant naître un prototype d'enclave économiquement active, telle que les Centres intégralement planifiés (CIP) qui sont le fruit d'une politique de développement touristique fomentée par l'État local et l'État Fédéral dans l'idée que ces capitaux génèrent des « cercles potentiels de développement économique».

Mots clefs : Région, État, tourisme, Pueto Vallarta

\section{DesenVolvimento interestatal DE PUERTo DE VAllarta E BAHIA DE BANDERAS: MÉXICO.}

\section{Resumo}

O objetivo deste trabalho consiste em mostrar que a consolidação dos capitais localizados na região costeira de ambos os municípios propicia uma complementaridade e compatibilidade entre a economia de mercado (interesses micro-empresariales exclusivos) e a política de ordenamento territorial (criação de Centros Integralmente Planejados) que gesta o Estado para consolidar os capitais turísticos na região. É através do acompanhamento entre os capitais estrangeiros e as políticas territoriais impulsionadas pelo Estado que se sustenta a atividade turística e que se tem o protótipo de um enclave econômico; como são os Centros Integralmente Planejados (CIP) que respondem a uma política de desenvolvimento turístico fomentado pelo estado Federal e local, apostando que estes capitais gerem "círculos virtuosos de desenvolvimento econômico".

Palavras-chave: Região, Estado, turismo, Puerto Vallarta

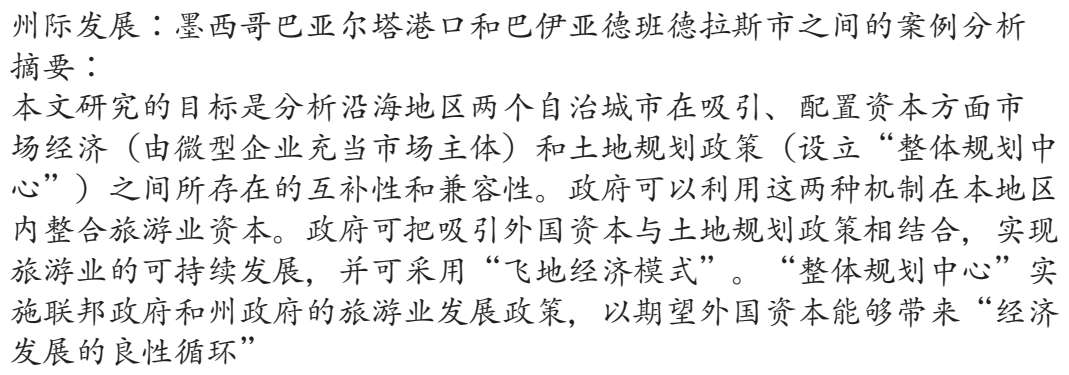




\section{INTRODUCCIÓN}

De acuerdo con el objetivo y el planteamiento de estudio se reconoce que no existe una concepción unívoca de región, sino que el concepto de región está sujeto al planteamiento teórico general del investigador, al problema específico que trata de resolver y, por consiguiente a la actitud metodológica adoptada (Merchand, M., 2007).

De antemano cabe decir que la definición de región se debate en medio de una polémica inagotable entre disciplinas y enfoques epistemológicos. Debido a la limitante de espacio y también porque no es lugar para entrar a las controvertidas disquisiciones argumentativas sobre el significado económico de región. Por consiguiente, si se considera que la región es un concepto heurístico, y su conceptualización debe partir del sujeto cognoscente, la definición práctica para acotar región, consistirá en interrelacionar cuatro instancias: empresas trasnacionales, ${ }^{2}$ Estado nacional, Estado local o estatal y la dinámica de la economía mundial. Como se muestra en la Figura 1.

Figura 1. Instancias que interactúan conjuntamente

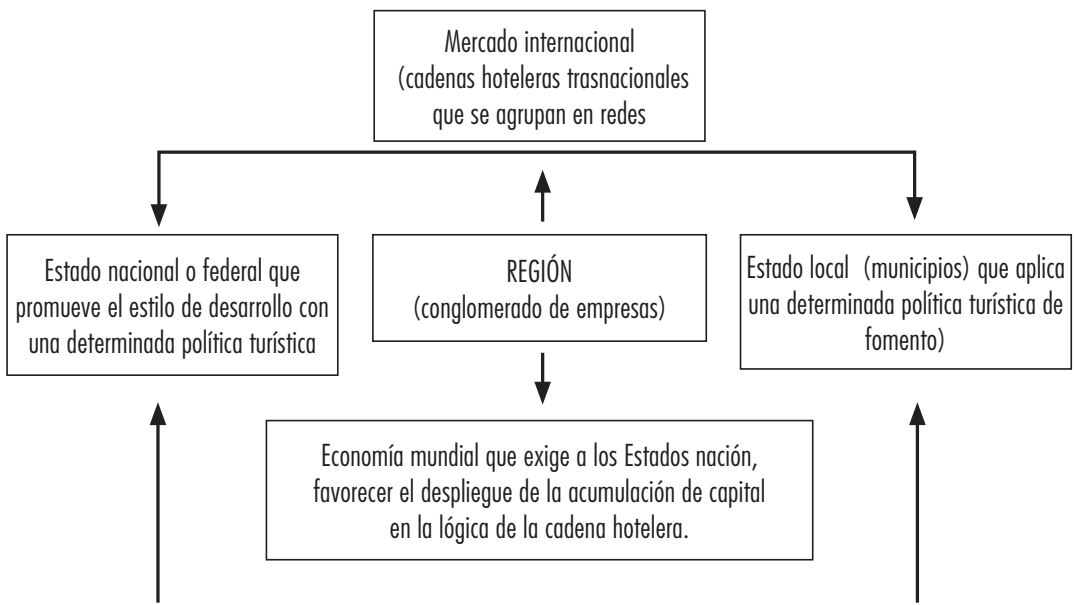

2 Existe una plena sincronía entre el interés de las empresas trasnacionales para fortalecer sus propios agrupamientos turísticos y el de los Estados-nación que propician condiciones favorables para el desarrollo de agrupamientos que tengan que ver con las actividades del ocio; en última instancia, la misión o compromiso del Estado nacional o estatal es la de promover un espacio fértil para segmentos turísticos competitivos internacionales. 
Marco A. Merchand Rojas

Estas cuatro instancias aplicadas vendrían a ser ilustrativas, pues definirían y configurarían espacialmente a la región en función de las interrelaciones entre estas instancias. Se propone también que para abarcar integralmente el concepto de región, se le integren tres dimensiones que interactúan: local, nacional e internacional, que es a final de cuentas, donde se concretan las estrategias de las cuatro instancias aludidas.

De ahí, se propone que para comprender la interacción entre los niveles regional, nacional e internacional se partirá de cuatro instancias que interactúan conjuntamente: empresas trasnacionales (empresas hoteleras que se agrupan en redes); Estado nacional, que se encarga de extender a todo el ámbito territorial el "estilo de desarrollo" promoviendo el turismo; ${ }^{3}$ Estado local o estatal, que se adapta a las exigencias nacionales adecuándolas a las propias particularidades regionales (se edifican enclaves turísticos), y Economía Mundial ${ }^{4}$ la que exige a los Estados-nación favorecer el despliegue de la acumulación del capital en la lógica de la cadena de valor global en las actividades turísticas.

En el transcurso de los seis apartados que integran este documento se argumenta que la construcción de región que se propone consiste en que cada sociedad organiza su espacio y le imprime una forma específica de configuración. Sin embargo, aunque los diferentes subsistemas o regiones se diferencian por el tipo de variante que acusen de la formación social en cuestión, estas formaciones sociales propias dependerán de las características y condicionantes económicas que desarrolle tanto el modelo nacional como internacional. Para

3 Las políticas turísticas que despliega el gobierno mexicano adquieren una importancia económica en función de la importancia que va tomando el turismo como generador de divisas (actualmente, dicha actividad es una de las primeras fuentes generadoras de divisas). De ahí que el Estado sea una instancia de promoción para captar divisas a partir de otorgar condiciones excepcionales de maniobra a la inversión extranjera y cuente ésta con las garantías legales suficientes para su instalación en los destinos turísticos de sol y playa.

4 La economía mundial es un concepto abstracto. El Sistema Monetario Internacional (sMI) y la División Internacional del Trabajo (DIT) dan a este concepto la realidad efectiva de los Estados-nación y de los intercambios entre las economías nacionales. La determinación que ejerce la economía mundial sobre las economías nacionales y la que ejercen las economías centrales sobre las economías periféricas, sólo pueden realizarse mediante la modificación de las reglas de funcionamiento tanto del SMI como de la DiT. De ahí, es posible deducir algo fundamental: que las estrategias por las cuales pueden optar los Estados-nación para la formulación de sus políticas económicas, están definidas por coacciones que se hacen sentir sobre los Estados a través del sMi y de la DiT. 
ejemplificar cómo estas formaciones sociales se configuran de distinta manera dependiendo de sus inercias externas e internas que desarrollen, se puede ilustrar el caso a partir de lo que pasa en México. Se tiene por ejemplo la formación económico-social o región norte del país, donde se asientan en su franja fronteriza empresas maquiladoras dedicadas a la manufactura en general y otra región muy distinta que se caracteriza por una franja costera que depende de la actividad turística.

Ahora bien, siendo más puntual para explicar nuestro objeto de estudio en torno al concepto de región, cabría preguntarse ¿cómo analizar una situación local en un contexto global (economía mundial)?

Para abordar esta problemática, deberemos ser lo suficientemente cautos para no explicar la realidad económica de la región sólo a partir del desempeño de la economía nacional en la cual está inmersa, sino también tomando en cuenta que su dinámica económica interna es arrastrada por los cambios que se registran en el entorno internacional. De ahí que las regiones se han convertido no sólo en subpartes del espacio nacional, sino en unidades del espacio internacional. En México, existen regiones que dependen más económicamente de las inversiones extranjeras, como es el caso de las regiones productoras de Commodities tradicionales agrícolas (zarzamora, brócoli, etcétera) y por supuesto también de enclaves turísticos que generan vínculos estrechos con las cadenas de valor global integradas por corporativos trasnacionales, ubicados en los países desarrollados (Merchand, M., 2006).

También se destaca la importancia que cobra y se le exige a los Estadosnación, favorecer el despliegue de la acumulación del capital en la lógica de la cadena de valor global en las actividades turísticas. En otras palabras, como lo explica Harvey, D. (2007) la soberanía del Estado sobre la circulación de mercancías y capitales es entregada en una actitud servicial al mercado global. El quid del asunto para David Harvey se encuentra en las soluciones espacio-temporales, porque generan demanda, tanto de inversión como de bienes de consumo en otros lugares, ejemplo: la actividad turística. Para mantener abiertas las oportunidades rentables es tan importante el acceso a inputs más baratos como el acceso a nuevos mercados, de lo que se desprende la necesidad de obligar a los territorios no sólo a comerciar (lo que efectivamente ayuda), sino también a permitir inversión de capital (cadenas hoteleras) en operaciones rentables utilizando la fuerza de trabajo, materias primas, tierra, etcétera.

En la exposición y las mismas conclusiones se insiste en explicar el papel central que juega la intervención del Estado mexicano para la conformación de nuevos emprendimientos turísticos a través de la planificación y el ordenamiento del espacio (ejemplos que ilustran tales emprendimientos son los complejos 
Marco A. Merchand Rojas

turísticos de Los Cabos San Lucas, Cancún, Nuevo Vallarta-Bahía de Banderas, etcétera).

Vale la pena citar textualmente a Jiménez, A. que acertadamente señala:

"De un territorio olvidado por la economía de producción industrial y agropecuaria, a un interés maximizado por el ocio y la valoración del clima y el paisaje. Los actores han sido sucesivamente, el Estado, que ha invertido una gran parte de dinero público en esa revaloración y más recientemente -con el modelo del liberalismo-, con los poseedores del capital, que se han apropiado del valor del territorio sin que parezcan interesados en contribuir a su preservación o mejora. En esta condición de explotación territorial y de poder de transformación, las cadenas hoteleras se han convertido en el eficaz instrumento de ese tránsito. En una síntesis del proceso que subyace en esas conductas se afirma que del ordenamiento territorial se ha pasado al ordeñamiento territorial... El turismo tiene en la hotelería, el más territorializado de sus actores; con ello, las cadenas hoteleras se vinculan con orientaciones, intereses y objetivos que están matizados por esta particularidad que les ancla, aunque sea temporalmente, al suelo donde operan. El poder político que manifies$\tan$ los inversionistas hoteleros extranjeros, se deriva de sus recursos monetarios y de sus relaciones tanto con el exterior como con los políticos en el poder, con los que tienen intereses, influencia y filiaciones. En realidad son caras de una misma moneda” (Jiménez, A., 2009: 114).

$\mathrm{Al}$ representar el turismo de sol y playa como uno de los más importantes segmentos de crecimiento y con el mayor volumen de demanda, se instrumentaron políticas que modificaron el esquema legal de las inversiones sobre todo con los destinos turísticos que ofrecen ventajas comparativas (mano de obra barata, recursos naturales). Para apoyar el desarrollo turístico se impulsó la inversión extranjera, que se complementaba con una importante inversión pública en infraestructura básica y de acceso, además del compromiso gubernamental de apoyo casi irrestricto, condiciones ideales para la inversión extranjera (IED). ${ }^{5}$

5 A inicios de los ochenta, la Inversión Extranjera Directa (IED) ya no representa una amenaza al desarrollo nacional, sino que se considera como una posibilidad real para competir en el mercado internacional. El contar con flujos de capitales externos, representa una vía de acceso a la tecnología extranjera y un medio para aumentar las inversiones productivas; el aspecto crucial fue la liberalización del régimen de inversión extranjera directa. Así, la restrictiva Ley sobre Inversión Extranjera Directa de 1973 fue reemplazada en 1984 por otra más liberal en su interpretación, en la cual se permitió la participación mayoritaria del capital extranjero (Merchand, 2002). 
El instrumento que liberalizó el mercado para beneficio no sólo del turismo, sino de otros sectores (agrícola e industrial) fue el que se implementó en el gobierno de Carlos Salinas con la reforma al Artículo 27 constitucional. Las modificaciones a ese Artículo y las derivaciones en la Ley Agraria, otorgaron derechos a los ejidatarios para enajenar o vender sus parcelas a Sociedades Mercantiles, a otros ejidatarios o a cualquier tercero. Esa modificación ha resultado en la venta de amplias zonas a particulares, incluidas algunas de litoral, cuya motivación fundamental es la de hacerlas turísticamente rentables. En otras palabras, las políticas territoriales de enfoque neoliberal han instrumentado una eliminación paulatina (desregulación) de trabas legales e institucionales que faciliten el libre movimiento de la producción, de las mercancías, el abaratamiento de la mano de obra, la obtención de recursos naturales, etcétera.

Sin embargo, el modelo tradicional de sol y playa se sigue incentivando, aunque es considerado el más depredador en términos ambientales. La expansión turística en áreas naturales biodiversas como las de la Costa Sur de Nayarit provoca múltiples transformaciones, no sólo de imagen, sino sobre todo sociales y culturales, económicas y por supuesto de sustentabilidad. Los Centros Integralmente Planeados incentivan el desarrollo de los resorts, éstos son expresión de conglomerados de grandes cadenas hoteleras que diversifican su accionar empresarial, mundial y localmente.

\section{LA OPERACIONALIZACIÓN DEL CONCEPTO DE REGIÓN A PARTIR DE LA NUEVA GEOGRAFÍA ECONÓMICA}

Sin lugar a dudas, el aporte teórico de P. Krugman (1992, 1995 y 1997) y el libro que publicó con Fujita y Venables (2000) para reconceptualizar el significado que adquiere la región son de suma importancia para ser tomados en cuenta (Merchand, M., 2007). Sin embargo, el planteamiento de Krugman no considera al Estado como una instancia que propicia encadenamientos empresariales. En este trabajo se propone la intervención del Estado como un agente facilitador o promotor de inversiones que propician o desencadenan procesos acumulativos de conglomerados empresariales (cadenas hoteleras retroalimentan concentraciones de empresas que ofrecen esparcimiento y recreo para un turismo nacional y extranjero de altos ingresos).

Ahora bien, los estudios realizados por Krugman coinciden muy bien con el objetivo general de este trabajo, pues se considera que todavía los siete principios geográficos (distancia, accesibilidad, interacción, difusión, transporte, ventaja comparativa y aglomeración) que han dirigido la localización de las actividades 
Marco A. Merchand Rojas

productivas (actividad turística) de la economía global deben estar presentes en el análisis de lo regional. Por supuesto que estos principios se hacen relevantes sin considerar la limitante de un plano isotrópico; el inicio de la ventaja de accesibilidad y aglomeración puede ser visto como histórico en su origen y acumulativo por naturaleza (Krugman, P., 2000).

Se conjetura que el crecimiento económico que acarrea el proceso de globalización a través de la reestructuración productiva mundial, conlleva a una agudización entre regiones en el mundo, conduciendo a una diferenciación entre ellas que se caracteriza por una elevada concentración económica en unas cuantas regiones y localidades urbanas, producto de las diferencias en la formación de áreas de mercado, la aglomeración de capital fijo y en las productividades globales y sectoriales de sus economías (fomento de la actividad turística). Sólo en ciertos lugares específicos de la geografía económica mundial se forman nodos hacia los cuales gravitan flujos de inversión, financieros y productivos que permiten consolidar centros de investigación y desarrollo tecnológico de vanguardia.

En efecto, como se ha explicado, el rasgo económico de una región está determinado a partir de las características predominantes de un desarrollo mundial que estructuralmente reproduce los desequilibrios económicos inter e intra, tanto al interior como al exterior de una región, agudizando las disparidades o divergencias entre ellas, en todos los órdenes, desde lo local, regional, nacional y mundial.

La pregunta central que hay que hacerse es ¿cuál sería la característica más prominente de la distribución geográfica de la actividad económica?

La Nueva Geografía Económica (NGE) ${ }^{6}$ representada por Paul Krugman (1997) se encargará de actualizar la importancia que tiene el territorio, pero con otros supuestos contrarios a los que consideran a la región como una planicie isotrópica.

La NGE es una síntesis entre aproximaciones económico-espaciales que, aunque nacidas dentro la misma corriente de pensamiento, eran en buena medida

6 Como el mismo Krugman, P. (1997) reconoce, los elementos postulados por la NGE no son completamente nuevos. En efecto, el concepto de las ventajas de aglomeración vinculadas a los rendimientos crecientes de escala, se remonta a las contribuciones de Marshall, a los modelos del geógrafo alemán de principios del siglo XIX Von Thünen y a los continuadores de la escuela de Jena, hasta llegar a la primera mitad del siglo xx con los influyentes geógrafos (Lösch y Christaller, W.). 
excluyentes; de ahí que la NGE introduzca una serie de fundamentos "microeconómicos" nuevos que se refieren:

- Ser parte de un enfoque de competencia imperfecta, que es fundamental, sobre todo en la conceptualización de las implicaciones localizadoras de la teoría de la producción.

- La competencia imperfecta se encuentra ligada a un esquema de rendimiento creciente. Esto también es importante porque son estos rendimientos crecientes los que favorecen la concentración de las actividades económicas en unos pocos espacios. Los rendimientos crecientes, son la principal fuerza centrípeta existente en el sistema.

- Se otorga una importancia central al proceso de externalidades como aquellos efectos positivos o negativos generados por una actividad o empresa sobre otras de su entorno, que provoca un aumento o disminución en su nivel de beneficio y/o utilidad, por lo que están relacionados de forma directa con la proximidad. La noción de externalidad, pese a tener un origen bastante lejano, recupera actualmente un notable protagonismo como principal factor explicativo de las tendencias favorables a la concentración espacial de actividades innovadoras, aspecto al que los geógrafos también han contribuido con la noción de campo de externalidad (Méndez, R., 1997).

- Se vincula la problemática localizatoria con otras áreas de trabajo y tradiciones de pensamiento económico. Es el caso de las teorías de comercio internacional y de las propias teorías del crecimiento. Los rendimientos crecientes explicarían, de esta forma, el crecimiento económico de los distintos territorios (y su tendencia general a la no-convergencia); el concepto de proceso acumulativo aludido más arriba, ilustra por ejemplo los procesos de aglomeración industrial.

- Incluso Krugman, P. (1995) sostiene que puede incrementarse nuestro conocimiento de la economía internacional estudiando economía regional. Krugman afirma que la economía internacional viene a ser en gran medida un caso espacial de la geografía económica y, por tanto, una de las mejores formas de comprender cómo funciona la economía internacional, reside en empezar observando qué sucede al interior de las naciones.

Krugman refuerza la idea en torno a la importancia que adquieren actualmente las regiones y explica que las regiones en el seno de un país tienden a estar más especializadas y comerciar más que los países, incluso cuando éstas poseen un tamaño tan grande como aquéllos; Krugman explica que:

[...] el desarrollo regional desigual puede determinarse por contingencias históricas. Por ejemplo la concentración masiva de población en el corredor del Nordeste 
Marco A. Merchand Rojas

de Estados Unidos se debe evidentemente no a los recursos naturales de la región sino al hecho histórico de que los inmigrantes europeos de los siglos XviI y XVIII se establecieron primero en las costas Este y los emplazamientos urbanos e industriales originarios tuvieron lugar a lo largo de la costa. Dentro de este cinturón urbano, Nueva York sigue siendo la ciudad más grande -en gran parte debido a que en 1820 el río Hudson (que desemboca en el mar en Nueva York) estaba unido a los grandes lagos por el Canal de Erie (1992: 17-19).

Esta cita se refuerza con la pregunta que se hace Krugman: ¿por qué están la riqueza y la población concentradas geográficamente? Los geógrafos señalan una variedad de formas mediante las cuales las ventajas iniciales de algunas localizaciones que pueden no representar más que un accidente histórico, tienden a reforzarse a lo largo del tiempo. A tales procesos que se autorrefuerzan se les denomina a menudo ejemplos de causación acumulativa; por ejemplo: los casos de centros vacacionales que albergan grandes cadenas hoteleras.

Una vez que una región tiene una alta concentración productiva ${ }^{7}$ este patrón tiende a ser acumulativo: la región dominante (Puerto Vallarta y Bahía de Banderas) adquiere una ventaja de localización, esto es, ella deviene atractiva para las firmas debido al gran número de firmas que ya producen allí (y no, por ejemplo, una mejor dotación de factores). En otras palabras, el éxito explica el éxito (Moncayo, 2003). El ejemplo más claro de causación acumulativa implica la interacción de las economías de escala, los costos de transporte y la movilidad de trabajo. Es decir, las economías regionales se caracterizan a menudo por el desarrollo desigual, un proceso de causación acumulativa en la que las regiones con una ventaja inicial debida a un accidente o la historia, atraen volúmenes crecientes de industria y empleo de otras regiones menos afortunadas.

Una implicación inmediata del capitalismo de mercado es su circularidad, es decir, las grandes empresas (cadenas hoteleras) desean localizarse en lugares

7 La concentración territorial nace, básicamente, de la interacción de los rendimientos crecientes, los costos de transporte y la demanda. Si las economías de escala son lo suficientemente grandes, cada fabricante prefiere abastecer el mercado nacional desde un único emplazamiento. Para minimizar los costos de transporte, se elige una ubicación que permita contar con una demanda grande. Pero la demanda local será precisamente grande, allí donde la mayoría de los fabricantes elijan ubicarse. De este modo existe un argumento circular que tiende a mantener la existencia de las concentraciones, una vez que éstas han sido creadas, manteniéndose y ensanchándose las diferencias con otras regiones. 
en que exista un alto potencial de mercado. Esto significa lugares próximos a grandes economías de escala. Además, los potenciales mercados y las economías de escala tienden a ser mayores en lugares donde se localice la mayor cantidad de empresas. Por lo tanto, existe una tendencia natural al auto-refuerzo regional del crecimiento de las economías, o a su declinación, que tiene como variable fundamental el potencial económico inicial que brinda el lugar y la ubicación de empresas.

Krugman se hace una serie de preguntas comunes a cualquier modelo: ¿cuándo se puede decir que es sostenible la concentración espacial de una actividad económica? Y si hubiera una concentración ¿̨cuáles serían las condiciones necesarias para que las ventajas por ella creadas, sirvieran para su mantenimiento? ¿Cuándo se puede decir que es inestable un equilibrio simétrico sin concentración espacial? ¿Cuáles son las condiciones para que aumenten las pequeñas diferencias entre localizaciones, de tal forma que, pasado cierto tiempo, se rompiera de forma espontánea la simetría entre las que eran idénticas? (Fujita, Krugman y Venables, 2001: 19).

Las respuestas a las preguntas giran en torno al equilibrio entre las fuerzas centrípetas, esto es, las que tienden a provocar una concentración espacial de la actividad económica, y las fuerzas centrífugas, que se oponen a dichas concentraciones. Para la NGE, el desarrollo económico es el resultado de la conjunción de fuerzas centrípetas y centrífugas. Las primeras provienen de la combinación de bajos costos de transporte y el aprovechamiento de economías de escala debido al tamaño del mercado en actividades con costos fijos elevados; los rendimientos crecientes elevan el tamaño de las regiones más industrializadas, incidiendo positivamente en el aumento del producto. El capital humano, las externalidades tecnológicas y los encadenamientos también se asociarían con la aglomeración, incidiendo positivamente en el crecimiento de la productividad.

Las fuerzas centrífugas se producen como resultado de la inmovilidad de los factores o debido a factores de congestión, como por ejemplo altos precios del suelo o restricciones a la movilidad de la mano de obra; es decir, por el surgimiento de dese-economías externas, aunque la diversificación y la especialización también posean un papel importante en el desarrollo económico asociado a la dispersión.

Por último, cabe decir, que la NGE sostiene que las economías de aglomeración (concentración de empresas turísticas, agrícolas e industriales) corroboran la hipótesis de la divergencia regional, es decir, de que el libre juego de las fuerzas del mercado conduce irremediablemente a una intensificación de las desigualdades regionales, acrecentando incluso la polarización, tal como lo habían planteado otros economistas. 
Marco A. Merchand Rojas

\section{REGIÓN ACOTADA POR LA RELACIÓN INTERESTATAL DE PUERTO VALLARTA Y BAHÍA DE BANDERAS}

La Región Interestatal de Puerto Vallarta y Bahía de Banderas, el concepto de región utilizado, se distingue del espacio por su homogeneidad interna (playa y sol) y por la ventaja que presenta la continuidad de playa de aproximadamente $15 \mathrm{~km}$ de Puerto Vallarta a Bahía de Banderas. Estas particularidades anunciadas le otorgan un carácter específico a la región aludida y delimitan su extensión a partir de las propias características socioeconómicas (perfil de ingreso, inversiones en el rubro turístico, PEA ocupada, etcétera).

De esta manera, el concepto de región -en forma implícita- se refiere a un agregado espacial significativo que concentra un polo o punto focal, donde su área de influencia acepta la existencia de tres tipos de regiones: Regiones homogéneas; Regiones nodales, polares o funcionales y Regiones Plan.

Para el caso del objeto de estudio propuesto, cabe señalar que estos tres tipos de regiones se operacionalizan en la región objeto de estudio pues Puerto Vallarta, como Nuevo Vallarta (Bahía de Banderas-Nayarit) son municipios que cuentan con las mismas condiciones geográficas y naturales (regiones homogéneas); también son nodales y polares ya que concentran una aglomeración de empresas que se ubican en una zona turística exclusiva y por supuesto son regiones Plan por parte del Estado federal, local y municipal para ser consideradas como instrumento de planeación turística que viabilice la instalación de conglomerados de cadenas hoteleras (Merchand, M., 2008).

Ahora bien, la región objeto de estudio cuenta con una riqueza ambiental y escénica integrada por cinco municipios con vínculos económicos intra e inter en el área de acción de Puerto Vallarta: Compostela, Bahía de Banderas en el estado de Nayarit y Cabo Corrientes, San Sebastián del Oeste y Puerto Vallarta en el estado de Jalisco. ${ }^{8}$ Estos municipios se caracterizan por ser una región homogénea en la que la dinámica de crecimiento de los servicios en el ámbito turístico se ha desbordado más allá del estado de Jalisco y, donde los municipios de Bahía de Banderas manifiestan especial crecimiento debido a la sobre demanda y la falta del suelo, dentro del municipio de Puerto Vallarta. San Sebastián del Oeste se ha repuntado como un atractivo de carácter urbano por la conservación; además

8 Programa de Ordenamiento de la Zona Metropolitana Inter-Estatal de Puerto Vallarta-Bahía de Banderas, documento técnico (diciembre 05 de 2007). 
de contar con áreas boscosas en el municipio de Cabo Corrientes (Jalisco), también ofrece una variedad significativa en cuanto a sitios de playa y zonas naturales con explotación de potencial turístico.

De la complejidad sobre el concepto de región aludida tendríamos tres niveles correspondientes que son: el nivel regional (cinco municipios), nivel metropolitano que comprende los municipios interestatales de Bahía de Banderas y Puerto Vallarta (microrregión objeto de este estudio) y el nivel conurbación (que corresponde a la unidad urbana formada por la población de Puerto Vallarta y Bahía de Banderas). Estos tres niveles descritos, se particularizan por sus ligas y actividades socioeconómicas a partir del fomento turístico.

\section{LA INSTAURACIÓN DEL CENTRO INTEGRALMENTE PLANEADO (CIP)}

Cabe destacar el caso del Municipio de Bahía de Banderas ${ }^{9}$ que fue creado por decreto ${ }^{10}$ con el objetivo de desarrollar el Centro Integralmente Planeado (CIP) de Punta de Mita; este cip da origen al Fideicomiso de Bahía de Banderas en 1970; el patrimonio de dicho Fideicomiso quedó constituido con un total de 4,136 hectáreas localizadas sobre aproximadamente $85 \mathrm{~km}$ de planicie costera, del entonces Municipio de Compostela (que incluye al actual Municipio Bahía de Banderas).

Se crea exprofeso por el Estado, una estrategia de desarrollo turístico que fomentara la instalación de empresas hoteleras acorde con las ventajas naturales del nuevo municipio de Bahía de Banderas. Para concretar el proyecto y de acuerdo con los intereses económicos que se generaron, el gobierno del estado justifica la expropiación de los pobladores naturales, argumentado cuestiones de

9 La región de Bahía de Banderas fue durante muchos ańos un territorio aislado, olvidado o desconocido, al igual que la mayor parte de las costas mexicanas, situación que comenzó a cambiar a partir de los años cuarenta y cincuenta, con la denominada "marcha al mar". A lo largo de 50 años las costas del Pacífico mexicano han logrado un cambio significativo, transformando algunas regiones en zonas de amplias perspectivas de desarrollo, sobre todo en la conocida como el Pacífico medio mexicano, en la que destaca el llamado Triángulo de Oro, compuesto por los estados de Jalisco, Colima y Nayarit.

10 Presidencia de la República, Decreto presidencial del 18 de noviembre de 1970, Diario Oficial de los Estados Unidos Mexicanos. 
Marco A. Merchand Rojas

localización y características naturales como detonantes no sólo del municipio en sí, sino de su área de influencia.

El Artículo Sexto del Decreto presidencial declara:

"Que es causa de utilidad pública y la expropiación por la creación o mejoramiento, así como el adecuado aprovechamiento de centros de población y sus fuentes propias de vida, así como el desarrollo de la industria turística, en la cual se han invertido sumas cuantiosas en obras de infraestructura y en la creación y desenvolvimiento de actividades que beneficien a la colectividad. Estas razones hacen necesaria y justifican plenamente la expropiación de terrenos a que se hace referencia a fin de realizarlas. [...] Se declara de utilidad pública el desarrollo habitacional y turístico en los terrenos que circundan la Bahía de Banderas ubicados en las costas de los estados de Nayarit y Jalisco y el mejoramientos de los centros de población de Puerto Vallarta, Jarretaderas, Bucerías, Cruz de Huanacaxtle, Higuera Blanca, Sayulita, Peñita de Jaltemba, Las Varas y El Capomo así como fuentes de vida..." (Decreto presidencial, 1970).

Cuadro 1. Expropiación de terrenos eijdales que integraron el patrimonio del fideicomiso de Bahía de Banderas

\begin{tabular}{|c|c|}
\hline Localidad & Hectáreas expropiadas \\
\hline Jarretaderas & 382 \\
\hline Bucerías & 440 \\
\hline Cruz de Huanacaxtle & 375 \\
\hline Higuera Blanca & 1,083 \\
\hline Sayulita & 544 \\
\hline Peñita de Jaltemba & 799 \\
\hline Las Varas & 184 \\
\hline El Capomo & 329 \\
\hline Total superficie & 4,136 \\
\hline
\end{tabular}

Fuente de datos: (FIBBA,1985).

A partir de este ejercicio expropiatorio a favor del fomento turístico se empieza a gestar un cambio de grandes magnitudes en el orden territorial que afecta la configuración de la franja costera. Por supuesto que los lugareños fueron replegados o confinados hacia otros lugares, incorporándose a las nuevas actividades económicas que generaría la actividad turística (construcción de infraestructura hotelera y servicios turísticos en general).

Vale la pena mencionar el caso de Punta de Mita que es una fracción del territorio correspondiente al Municipio de Bahía de Banderas localizado en la 
Región Costa Sur del Estado de Nayarit. En 1989 se promovió la división del municipio de Compostela; la parte norte conservó el mismo nombre y a la parte sur se le nombró Bahía de Banderas. La microrregión de Punta de Mita está circunscrita por las localidades de Higuera Blanca al Norte y de Nuevo Corral del Risco contiguo con el Fraccionamiento Emiliano Zapata al Sur; en sus inmediaciones se construye el Centro Integralmente Planeado (CIP) bautizado por "Litibú".

Ahora bien, para operacionalizar el cIP se instrumenta el Programa de Ordenamiento de la Zona Metropolitana Inter-Estatal de Puerto VallartaBahía de Banderas. ${ }^{11}$ Este Programa contempló la Zona Metropolitana de Puerto Vallarta y Bahía de Banderas y conformaría lo que se suele llamar una microrregión, pues ambos municipios se vinculan estrechamente con una problemática común a través de compartir condiciones naturales iguales (zona costera ambiental y escénica), además de aspectos muy similares en el plano urbano-económico que hacen albergar las problemáticas de crecimiento turístico.

La expansión urbana de la ciudad de Puerto Vallarta hacia los municipios colindantes ha propiciado una conurbación ${ }^{12}$ de carácter interestatal con Bahía de Banderas; así la zona urbana de Puerto Vallarta se ha tomado como una ciudad cabecera o central donde se ha desarrollado una presión urbana sobre suelo disponible con otros municipios colindantes.

A la presión que ejerce Puerto Vallarta sobre las poblaciones colindantes se le denominará primacía; la cual puede ser tratada en dos dimensiones: como indicador demográfico de la concentración urbana de la ciudad de mayor tamaño en relación con las otras del sistema; y, como una dominación vertical sobre el resto de las ciudades del sistema, a través del proceso de centralización (Pozos, 1991; Unikel et al, 1978) $\cdot{ }^{13}$ La primacía es observada mediante

11 Documento técnico (diciembre 05 de 2007) que integra la normatividad para el ordenamiento territorial.

12 El proceso de conurbación hace referencia al crecimiento económico, poblacional y físico de la ciudad, mediante el cual se da la incorporación o integración de áreas circundantes que antes estaban limitadas por usos del suelo no urbanos y que debido a los corredores de transporte propician el uso urbanizado de los mismos. La contigüidad física de esas áreas se da mediante la conexión que propician los corredores y vías de transporte con las áreas urbanas más distantes.

13 Citados por Carrillo, S. (2007). 
el análisis poblacional y la centralidad ${ }^{14}$ interesa medirla a través de indicadores de la ocupación en actividades económicas de servicios productivos y de los grupos de ocupación profesional y directivo, con objeto de examinar preferentemente la centralidad de funciones urbanas más dinámicas, de gran valor agregado y posiblemente más vinculadas a la economía global.

Como lo señala S. Carrillo (2007) Puerto Vallarta es un subsistema que forma parte del sistema de ciudades de la Región Occidente que centraliza un dinámico eje costero con Bahía de Banderas en el vecino estado de Nayarit. La centralidad de Puerto Vallarta es generada por el alto grado de especialización en las actividades turísticas (en particular, hotelería) cuyos mercados son a escalas nacional e internacional y su dinámica de centralización está por tanto supeditada a la suerte de esta actividad. La importancia que muestra la tasa media anual de crecimiento sobre el índice de centralidad para ramas del sector turístico en Puerto Vallarta es de los más altos, equiparándose con el de la Zona Metropolitana de Guadalajara en 4.2\% de 1998-2003.

Respecto al índice de especialización económica, destaca Puerto Vallarta en el subsector de la rama 7211 (hoteles y moteles) en 2003, con la mayor población ocupada en este ramo (Garza y Rivera, 1994).

De hecho, la relación inter-estatal entre los municipios (Puerto Vallarta y Bahía de Banderas) se ha legalizado e incluso ha cobrado importancia, no sólo económica sino política. A partir de determinadas políticas con sesgo más

14 S., Carrillo (2007: 8) explica cómo se estima la centralidad: "ésta es indirectamente calculada mediante la sumatoria de las proporciones de cada ciudad respecto del total correspondiente a la región Occidente de la población ocupada en distintas actividades de servicios de mayor nivel de especialización y que, en cierta medida, satisfacen la demanda externa a la ciudad donde se ubican. La fórmula es la siguiente: (poij/poir), donde: Poij=Población ocupada en el sector i (o subsector o rama) de actividad de la ciudad $\mathrm{j}$. Poir = Población ocupada en el subsector i (o subsector o rama) de actividad de la región occidente. Las fuentes son los censos económicos de 1986, 1994, 1999 y 2004 (registrando datos de un ańo anterior, respectivamente). Esta sumatoria proporcional es sensible a la mayor o menor desagregación de categorías de actividades; de esta forma, ciudades con alta participación en actividades más específicas y especializadas (de escaso número de establecimientos y de reducida cantidad de ocupados) logran un índice de centralidad mayor, a pesar de contener relativamente menos población ocupada (o establecimientos) en total. Se incorporan selectivamente sectores o ramas de actividad que tienen mayor probabilidad de representar una función de centralidad, es decir, cuyo desarrollo se define en función no sólo de la demanda local, sino también regional e incluso internacional". 
sectorial (actividades de fomento turístico) que territorial, se promueven entre los dos gobiernos (Jalisco y Nayarit) a través del gobierno federal instrumentos de carácter regional que permitan consolidar inversiones extranjeras en el rubro de las actividades turísticas. ¿En qué han consistido en términos formales, los pactos o acuerdos entre los dos gobiernos para concretar las acciones en los programas y planes que otorgan direccionalidad al fomento del turismo entre Puerto Vallarta y Bahía de Banderas?

Los pactos o acuerdos interestatales tienen que ver con el acuerdo establecido entre los estados de Jalisco y Nayarit para sincronizar políticas de acuerdo con la intención de llevar a cabo el llamado "Programa de Ordenación de la Zona Metropolitana Inter-estatal de Puerto Vallarta y Bahía de Banderas" que consiste en tratar en común la problemática de los procesos socio-urbanos que se gestan entre los municipios aludidos. ${ }^{15}$

Dicho "Programa de Ordenamiento Territorial" propuesto por ambos estados, pretende atender dos situaciones comunes que se generan entre el municipio de Puerto Vallarta y Bahía de Banderas:

- Resolver de manera conjunta la problemática que representa la continuidad urbana y los flujos de mercancías que se hacen presentes en la parte central de conurbación de Puerto Vallarta y Bahía de Banderas.

- Considerar el aprovechamiento del potencial turístico de ambos municipios definiendo acciones concretas y partidas financieras para su gestión.

De antemano se adelanta el supuesto de que estas acciones referidas políticamente han representado la justificante de la propuesta por parte de los dos gobiernos estatales de normativizar programas y proyectos regionales que sustenten la actividad turística en la región.

La cuestión para explicar ahora es cómo se inscriben dichos programas y planes que legitiman y acotan el tratamiento de una región plan ${ }^{16}$ que consolide y potencialice el fomento del turismo como una actividad que "propiciará supuestamente el crecimiento económico".

15 "Programa de Ordenamiento de la Zona Metropolitana Inter-estatal de Puerto Vallarta-Bahía de Banderas", diciembre 05 de 2007.

16 Cuando hablo de región plan me refiero a las estrategias de política regional que emplea el Estado para fomentar una cierta actividad productiva en la región, creando todas las condiciones económicas y por supuesto legales que incentiven la llegada de capitales extranjeros en la región. 
Marco A. Merchand Rojas

\section{LOS PROGRAMAS Y LOS PLANES MUNICIPALES QUE ACOTAN REGIÓN A PARTIR DEL CIP}

Como explica el "Programa de Ordenamiento de la Zona Metropolitana Interestatal de Puerto Vallarta-Bahía de Banderas" los antecedentes de este proyecto se remiten a 1999 cuando nueve estados de la Región Centro Occidente (RCO) impulsaron un "proceso de promoción del desarrollo regional" en el que participaron los estados de Aguascalientes, Colima, Guanajuato, Jalisco, Michoacán, Nayarit, Querétaro, San Luis Potosí y Zacatecas. ${ }^{17}$

Incluso se ratifican los acuerdos del estado de Jalisco y Nayarit a través del Plan Nacional de Desarrollo Urbano de Ordenamiento Territorial (PNDU-OT 2001-2006) con la finalidad de instrumentar programas y proyectos estratégicos que detonen el desarrollo regional inter-estatal acorde con la vocación económica específica de la mesorregión (regiones interestatales con vocación turística).

En esta dinámica de gestión mesorregional quedan plasmados los planes y programas interestatales entre los gobiernos de Nayarit y Jalisco como son: el Programa a Zonas con Litoral de Jalisco y Nayarit y el Plan Maestro de Desarrollo Urbano Turístico de Bahía Banderas y Puerto Vallarta.

La justificante para llevar a cabo los programas interestatales se explica en razón de que los municipios colindantes de Bahía de Banderas y Puerto Vallarta propician inercias de crecimiento a partir de la centralidad que ejerce Puerto Vallarta y su zona de influencia (Merchand, M., 2008).

Pero independientemente de las bondades o desventajas de los CIP, ${ }^{18}$ las inversiones que se anuncian y que se llevan a cabo parcialmente por los tres niveles de gobierno (federal, estatal y municipal), tienen relevancia no sólo por el significado económico en sí, sino por las estrategias con carácter regional que instrumenta el Estado para detonar el llamado corredor turístico. Como ya se ha mencionado, el instrumento político que oficializa el compromiso del Estado para impulsar el corredor turístico, es a través del Programa de Ordenación de la Zona Metropolitana Inter-estatal de Puerto Vallarta y Bahía de Banderas; y por supuesto a través de la propia Secretaría de Turismo (2007), que es la encargada de operar los recursos financieros para proyectar el llamado corredor turístico

17 En el "Programa de Ordenamiento" se cita el acuerdo suscrito el 2 de septiembre entre los secretarios de Desarrollo Urbano de la Región Occidente y Centro-Norte para la formulación y ejecución de una estrategia regional de ordenamiento territorial.

18 Se tendría que realizar una evaluación económica de cuáles serían los efectos positivos y negativos de dichos CIP, pero este cometido rebasa al presente trabajo. 
de Puerto Vallarta-Bahía de Banderas, reafirma la idea de consolidar este corredor turístico con la inversión futura que el Estado federal instrumente y permitir así, detonar el corredor turístico.

El corredor turístico Puerto Vallarta-Bahía de Banderas-Compostela-San Blas, está concebido para fomentar los segmentos de: golf, naturaleza, cultura, náutico e inmobiliario; estará dotado con los mejores servicios y vías de comunicación de tal modo que se prevé que se consolide, en los años por venir, como un destino moderno y altamente competitivo en el Pacífico mexicano.

Para concretar estos proyectos, los titulares de la Secretaría de Turismo, del gobierno federal y del Fondo Nacional de Fomento al Turismo (FOnATUR), estiman que en la conurbación de Puerto Vallarta y Bahía de Banderas de 2007 a 2015, se hará una inversión de 485.10 MDD (millones de dólares) en infraestructura. De estos 485.10 MDD de recursos públicos para infraestructura, 241.42 serán programados por la Federación; 132.31 por el gobierno estatal, y 101.83 serán de origen municipal. Se tiene programado, de acuerdo con la idea de construir Centros Integralmente Planeados (CIP), que éstos se asienten en una reserva territorial de 435 hectáreas, el cIP de Nayarit contará con 10,000 cuartos de alojamiento, dos campos de golf de18 hoyos; el cip Litibú contará con clubes de playa, centros comerciales y de entretenimiento y un parque temático marino de cobertura regional. Los Cip de Nayarit constan de dos secciones: el Capomo y Litibú, cuya primera etapa prevé la inversión pública ejecutada por FONATUR de 63.7 MDD de los cuales, según declaraciones hechas por el propio FONATUR, se ha invertido ya el $90 \%$ de lo estimado. ${ }^{19}$

Sin embargo, las ventajas que anuncia el Estado para el beneficio de los pobladores y la sustentabilidad integral que se espera lograr con los proyectos de

19 El gobernador de Nayarit (Ney González Sánchez) explica el surgimiento de nuevos destinos turísticos, tal y como los que están en marcha en los complejos Litibú y El Capomo, los cuales forman parte del Centro Integralmente Planeado Nayarit. La primera etapa de construcción, dijo el funcionario, se realiza en el Complejo Litibú, el cual se encuentra ubicado a 2 kilómetros de Punta Mita y consiste en 4 mil 100 unidades de alojamiento, entre las cuales se incluyen 910 residencias turísticas, mientras que la segunda fase se levantará en El Capomo y comprenderá 5 mil 900 unidades de alojamiento. Además de las bondades de estos proyectos turísticos impulsados por el estado local, también explicó que el Centro Integralmente Planeado comprende una serie de desarrollos de muy alto nivel turístico, en conjunto con el desarrollo comunitario y de amplio beneficio social en su entorno, dentro de un plan maestro que abarca a los municipios de Bahía de Banderas, Compostela y San Blas, orientado a los segmentos de mercado de alto gasto, por lo que la oferta incluye golf, naturaleza, entretenimiento náutico y vivienda turística residencial, aprovechando la rápida dinámica de crecimiento turístico pero con un bajo impacto sobre la naturaleza. 
Marco A. Merchand Rojas

los CIP, contrasta con otras visiones externas que sostienen que los posibles beneficios no son los esperados. La Alianza de la Costa Verde, ${ }^{20}$ una agrupación que reúne a diversas organizaciones no gubernamentales de la región ha cuestionado de forma sistemática el proyecto, no sólo por sus propias inconsistencias, sino por su inserción descuidada dentro de una región de naturaleza frágil.

Además, los ecologistas lidereados por la Alianza de la Costa Verde destacan anomalías: se plantean densidades de hasta 60 cuartos por hectárea y seis niveles de construcción, contra un Plan de Desarrollo Urbano que sólo prevé cuatro pisos y 25 cuartos. De acuerdo con las opiniones de esta Alianza de la Costa Verde existe una serie de omisiones: el proyecto Litibú no establece los impactos acumulativos que se darán en toda la región como resultado de la creación del centro turístico, se elevaron ilegalmente las densidades, faltan áreas de donación para servicios públicos y espacios verdes, el terreno fue vendido antes de la aprobación del plan parcial, "no existen vialidades colectoras que delimiten los lotes de los condominios y de los hoteles"; tampoco está claro si se respetará el libre acceso al mar que establece la Constitución Política de México.

\section{LA DINÁMICA POBLACIONAL Y CADENAS HOTELERAS EN LA RELACIÓN INTER-ESTATAL DE AMBOS MUNICIPIOS}

En este apartado, se hará un breve análisis de la importancia del número de pobladores y su ocupación por actividad económica a partir de la evolución del turismo en la región.

Como se muestra en el Cuadro 1 respecto al estado de Nayarit, se registra una tasa de crecimiento de apenas $0.63 \%$ en 2005, en cambio en la región Costa Sur conformada por los municipios de Bahía de Banderas ${ }^{21}$ y Compostela se registra una tasa de crecimiento muy dispar, pues mientras en Compostela se

20 http://www.verdebandera.com/2008/01/litib-el-megaproyecto-cuestionado-del.html.

21 La dinámica de crecimiento del municipio de Bahía de Banderas se refleja claramente en su densidad demográfica; para el año 2000 era superior en casi un 90\%, en relación a la del municipio de Compostela; dicho crecimiento ha rebasado el desarrollo de los servicios y de infraestructura, como hospitales, bancos, carreteras, drenaje, etcétera. Cabe insistir que el Plan Estatal de Desarrollo 2005-2011 indica que en materia de migración estatal e internacional, la posición de la Región Costa Sur, se ubica en un promedio de $9.1 \%$, muy por arriba de la media estatal que es de $4.8 \%$. Particularmente tenemos que el $51.4 \%$ de la población que habita en Bahía de Banderas nació en otra entidad, lo cual está directamente asociado al crecimiento turístico del municipio (Gobierno de Nayarit, 2005). 
Cuadro 1. Dinámica demográfica

\begin{tabular}{lrrrrr}
\hline \multicolumn{1}{c}{ Entidad municipio } & 1990 & 2000 & $\begin{array}{c}\text { TMCA } \\
1990-2000\end{array}$ & 2005 & TMCA \\
\hline Nayarit & 824,643 & 920,185 & $1 \%$ & 949,684 & $0.63 \%$ \\
Municipio (Compostela) & 60,926 & 65,943 & $0.79 \%$ & 62,925 & $0.93 \%$ \\
Municipio (Bahía de Banderas) & 39,831 & 59,808 & $4 \%$ & 83,739 & $7 \%$ \\
Jalisco & $5,302,689$ & $6,322,002$ & $2 \%$ & $6,752,113$ & $4 \%$ \\
Municipio (Puerto Vallarta) & 111,457 & 184,728 & $5 \%$ & 220,368 & $4 \%$ \\
\hline
\end{tabular}

INEGI: Conteo de población y vivienda, 2005.

mantiene en 2005 un crecimiento poblacional muy bajo de $0.93 \%$, en el municipio de Bahía de Banderas, la población crece a una tasa de 7\%.

El crecimiento demográfico de esta región ha aumentado en promedio en un 9.3\% de 2000 al 2005. Sólo en 2005 la región mostraba 8.5\% de crecimiento poblacional, pues de acuerdo con el diagnóstico del Plan Estatal de Nayarit este crecimiento provenía del fenómeno de la migración hacia la región. ${ }^{22} \mathrm{El}$ municipio de Bahía de Banderas es el que más contribuye a este indicador, ya que el $52 \%$ de la población que lo habitaba en 2005, había nacido en otra entidad, fenómeno que se asocia directamente al crecimiento turístico del municipio. De acuerdo con información a partir del Plan Estatal de Nayarit, Bahía de Banderas recibe un flujo migratorio consistente de aproximadamente 10,000 habitantes por año, que se reparte principalmente entre los municipios de Puerto Vallarta y Bahía de Banderas.

En lo que refiere a Puerto Vallarta, este municipio ha registrado un crecimiento acelerado de su población, manifestándose en promedio del 2000 al 2005 una tasa de $31 \%$ en sólo un quinquenio. De acuerdo con el Instituto Nacional de Estadística, Geográfica e Informática (INEGI) sobre el conteo de población y vivienda de 2005, los municipios del área de estudio que concentran más población en áreas urbanas son: Bahía de Banderas con 77\%, le sigue Compostela con $63 \%$ y Puerto Vallarta con $97 \%$. Respecto a los resultados generales de los Censos Económicos de Jalisco y Nayarit de 2004 en términos de ocupación de mano de obra por sector productivo se reporta que el $88 \%$ de la población de Puerto Vallarta se emplea en la actividad del comercio y los servicios dedicados

22 Plan Estatal de Desarrollo, Gobierno del Estado de Nayarit 2005-2011. 
a la atención de la actividad turística; la misma tendencia sucede con Bahía de Banderas con $82 \%$ de la población ocupada en el sector terciario.

La importancia que adquiere la actividad turística en cuanto al desarrollo de infraestructura en ambos municipios se muestra con los siguientes porcentajes. Acorde con los datos manejados por la Secretaría de Turismo, se reporta en el 2004 que el 62\% de los establecimientos de hospedaje del estado de Nayarit se concentraba en la región costa sur (Compostela y Bahía de Banderas) ${ }^{23}$ de éstos, el 85\% de los hoteles de cinco estrellas se localizan en Bahía de Banderas, el $59 \%$ de los de 4 estrellas y el 69\% de los de tres estrellas. Respecto a los restaurantes de categoría turística, la cuarta parte se localiza en esta región. En el caso de Puerto Vallarta, esta región concentra el 44\% de los de Gran turismo del estado de Jalisco, el $25 \%$ de la oferta de cinco estrellas, el $22 \%$ de cuatro y $17 \%$ de 3 estrellas; en cuanto a la tipología de condominios compartidos, Puerto Vallarta abarca el $96 \%$ y el $34 \%$ de suites con las que cuenta el estado de Jalisco.

Respecto a la inversión hotelera en el país, en los últimos 20 años y en la región objeto de estudio, ésta se ha concentrado en el número de cuartos edificados. En el siguiente cuadro, se muestra cuáles son los países más importantes en términos de número de cuartos y de hoteles en México. Aquí faltaría realizar un estimado de cuánto le correspondería respecto al 100\% del total a Puerto Vallarta y Bahía de Banderas como destinos de sol y playa.

En síntesis, hemos visto cómo el estilo de desarrollo ${ }^{24}$ adoptado por el Estado y, utilizando una definición de Aníbal Pinto, tiene el objetivo de provocar efectos

23 En la Riviera Nayarita a la inversión turística se ha traducido en la llamada burbuja inmobiliaria que en los últimos años ha llevado a los desarrolladores a concentrarse en construir vivienda plus para los sectores altos y medio-altos. Entre los diversos desarrollos, se cubren las membrecía (propiedad de suites), los tiempos compartidos y la hotelería clásica de hospedaje, alimentación y diversión de sol y playa; éste se ha convertido en el modelo de desarrollo definido para la Costa Sur de Nayarit. Se ha propiciado la construcción de otros nichos comerciales para los segmentos sociales bajos, constituidos por los migrantes del ocio quienes se encargan de servir al turismo, segmento social en crecimiento y por ello, no es nada despreciable, si se considera la magnitud de la inmigración interna de mexicanos y en menor dimensión de extranjeros que llegan a ocupar puestos de trabajo en las empresas turísticas (Castellanos y Pedreńo, 2006). Los braceros del ocio demandan al mercado inmobiliario el alquiler de vivienda y la adquisición de la primera vivienda, convirtiéndose en un desafío para las autoridades y los inversionistas por el acelerado crecimiento poblacional de la Costera Sur de Nayarit.

24 En el aspecto económico, Aníbal Pinto define el "estilo de desarrollo" como "la manera en que dentro de un determinado sistema se organizan y asignan los recursos humanos y materiales con el objeto de resolver las interrogantes sobre qué, para quiénes y cómo producir los bienes y servicios" (Pinto, 1976). 
Cuadro 2. Oferta de cadenas hoteleras en México por país de origen de la cadena: promedio de cuartos por hotel (2006)

\begin{tabular}{|l|r|r|r|r|c|}
\hline País de origen de la cadena & Cuartos & Hoteles & Cuartos & Hoteles & $\begin{array}{c}\text { Promedio de cuartos } \\
\text { por hotel }\end{array}$ \\
\hline EUA & 26,891 & 167 & $31.9 \%$ & $43.3 \%$ & \\
\hline GB & 18,137 & 114 & $21.5 \%$ & $29.5 \%$ & 159 \\
\hline España & 33,448 & 83 & $39.6 \%$ & $21.5 \%$ & 403 \\
\hline Francia & 1,502 & 11 & $1.8 \%$ & $2.8 \%$ & 137 \\
\hline Canadá & 2,131 & 5 & $2.5 \%$ & $1.3 \%$ & 426 \\
\hline Colombia & 860 & 2 & $1.0 \%$ & $0.5 \%$ & 430 \\
\hline Países Bajos & 559 & 2 & $0.7 \%$ & $0.5 \%$ & 280 \\
\hline Japón & 752 & 1 & $0.9 \%$ & $0.3 \%$ & 752 \\
\hline Hong Kong & 128 & 1 & $0.2 \%$ & $0.3 \%$ & 128 \\
\hline Total & 84,408 & 386 & $100.0 \%$ & $100.0 \%$ & 219 \\
\hline
\end{tabular}

Fuente: Jiménez, A., 2009.

económico-productivos sesgados a la IED. Un ejemplo que ilustra muy bien lo señalado, es que partir de los cambios normativos a favor de la IED, se fortalece el liderazgo de algunas trasnacionales para comandar agrupamientos productivos agrícolas, industriales y turísticos. Éstos se expresan territorialmente, acordes con las necesidades que justifican una política sectorial de promoción e incentivo para que se instalen capitales que ofrecen de alguna forma "crecimiento económico en la localidad".

\section{CONCLUSIONES}

La pregunta que salta a lo largo de la exposición es si todavía la función del Estado sigue siendo la promoción de espacios económicos con el objetivo de promover crecimiento. La respuesta sería afirmativa, lo que indicaría que todavía el Estado hace regiones, para que después las inversiones privadas sobre todo extranjeras consoliden (aglomeraciones y/clúster) lo que el Estado inició, con la idea de que el impulso de las inversiones foráneas, una vez posesionadas de los CIP, al menos incentiven crecimiento económico 
Marco A. Merchand Rojas

Precisamente uno de los objetivos básicos, dentro de las funciones de un nuevo Estado, ${ }^{25}$ es que éste establezca las reglas del juego que permitan la existencia de regímenes especiales para hacer atractiva la llegada de capitales en sectores percibidos como prioritarios para el desarrollo de una determinada región. Sin embargo, como considera la propia CEPAL (2006), la reducción de impuestos, la utilización de subsidios y la promulgación de exenciones tributarias, destinadas a atraer inversiones a proyectos que involucren el manejo de recursos naturales no garantiza para nada, promover el desarrollo de instrumentos que ayuden a cuantificar e internalizar los costos sociales que involucra la explotación de dichos recursos naturales.

Por supuesto que las medidas de promoción a la inversión extranjera o nacional, no pueden desvincularse de normas que permitan una adecuada y rigurosa protección del patrimonio integral (natural, cultural, social, etcétera) de la sociedad.

Así que las regiones con potencial productivo a favor de la IED, estarían acotadas en áreas específicas para albergar determinados conglomerados de empresas en sectores específicos (electrodomésticos, automotriz y la producción agrícola más rentable; hortalizas, flores y frutas, y por supuesto, el fomento de actividades turísticas). Aquí, encontraríamos la configuración de una región a través de una red de empresas que tienen que ver más con una producción mundializada, que con el mismo país receptor.

El papel del Estado federal y local es fundamental para que dichas empresas se asienten sin ningún problema, ya que hay que crear un clima de negocios benigno para que el estilo de desarrollo trasnacionalizador se estabilice a favor de un modelo turístico trasnacionalizado que supuestamente "traerá efectos multiplicadores en el empleo e ingreso". El Estado no está para obstaculizar la llegada de estas empresas, sino para otorgar las condiciones idóneas (legales) que propicien su instalación para configurar conglomerados de cadenas hoteleras.

Por último, respecto a los impactos económicos del turismo se pueden clasificar en positivos y negativos; los primeros se refieren a la entrada de divisas,

25 'Al Estado se le asignó un rol 'subsidiario', hecho que connota una visión residual de las políticas públicas, pues al Estado sólo le corresponde actuar allí donde el mercado no llega. El Estado debía limitarse a mantener el orden interno y externo y a la realización de tareas de asistencia social. Por ello, se instrumentaron medidas orientadas a restringir al máximo posible las regulaciones, arbitrajes e intervenciones estatales en el desempeño de la actividad económica privada. Las nuevas medidas atraerían los capitales privados, en particular, las inversiones extranjeras directas" (Ruiz, C., 2002). 
generación de empleos, mejoramiento de la infraestructura, estímulo a la actividad empresarial, dinámica económica regional; entre los impactos negativos más significativos se encuentran el incremento de las importaciones, distorsiones en el mercado laboral, insuficiente infraestructura de servicios públicos, insuficiente vivienda, inflación, alta especulación sobre las tierras y bienes inmobiliarios. Por lo que toca al ámbito espacial, el turismo como creador, consumidor y destructor de espacios ejerce una gran influencia y modifica por lo general las estructuras regionales, genera grandes concentraciones derivadas de procesos migratorios de zonas rurales hacia centros de actividad turística, con las consecuencias lógicas con respecto a los servicios públicos de agua, drenaje, vivienda, electrificación, etcétera, promoviendo la construcción de ciudades que por lo general en países en desarrollo se manifiestan con alto grado de desorden y caos.

La propia Organización Mundial del Turismo (OMT) reconoce que son los intereses privados extranjeros los que mueven el turismo y es difícil incrementar los beneficios económicos locales porque los propietarios son en gran medida extranjeros, lo que significa que las fugas son cuantiosas y las conexiones locales escasas. ${ }^{26}$

\section{BIBLIOGRAFÍA}

Carrillo, S., Urbanización y globalización en el Occidente de México. http://www. sicbasa.com/tuto/AMECIDER,2007.

Castellano, M. y A. Pedreño, Los nuevos braceros del ocio. Sonrisas, cuerpos flexibles e identidad de empresa en el sector turístico, Mino y Dávila Editores, Madrid, 2006.

CEPAL, "La inversión extranjera en América Latina y El Caribe, 2003", cepaL, Santiago de Chile, 2006.

26 El concepto de "fuga" se refiere a las cantidades gastadas en la importación y servicios para satisfacer las necesidades del turismo. Las fugas de las rentas derivadas del turismo en un área económica local se producen cuando las conexiones económicas locales son débiles. El término conexiones se refiere a potencializar los beneficios económicos para la comunidad local y mejorar la reducción de la pobreza consistente en incrementar el alcance de las conexiones entre el sector estructurado (hoteles, otros alojamientos, restaurantes, turis-operadores, y transportes) y la economía local. Si aumentan las conexiones con la economía local disminuirán por consecuencia las fugas. 
Marco A. Merchand Rojas

Fujita, M., P. Krugman, y A. Venables, Economía espacial. Las ciudades, las regiones y el comercio internacional, Ariel Economía, Barcelona, España, 2000. INEGI, Conteo de población y vivienda, 2005.

Garza y Rivera, Dinámica macroeconómica de las ciudades en México, Tomo I, INEGI-COLMEX-IIS-UNAM, 1994.

Harvey, David, Espacios del capital, Akal, España, 2007.

París, capital de la modernidad, Akal, Madrid, España, 2008.

Jiménez, Alfonso, Cadenas hoteleras: estrategias y territorio en El Caribe mexicano, Tesis para obtener el grado de doctor en Geografía, unam, 2009.

Longás, J., Formas organizativas y espacio: los distritos industriales, un caso particular en el desarrollo regional, Estudios Regionales núm. 48, España, 1997.

Merchand, M., Los efectos de las transnacionales en el patrón cultivos de la zarzamora en el municipio Los Reyes, Michoacán, México, ponencia presentada en el vir Congreso Latino Americano de Sociología Rural, Ecuador, Quito, 2006.

, Convergencia entre teorías que explican por qué hay territorios ganadores y otros perdedores, UAM-A, 2007.

, Conceptos y teorías de economía regional: estudios de caso, Universidad de Guadalajara, 2007.

, “¿Puerto de Vallarta, un espacio sostenible o en declive?”, capítulo de libro, editado por la Universidad de Guadalajara, Centro Universitario de la Costa, 2008.

, "La ausencia de un desarrollo regional y su reemplazo por un limitado crecimiento sectorial en Colima", México, Revista Economía, Universidad Autónoma de Yucatán, 2008.

Moncayo, E., Evolución de los paradigmas y modelos interpretativos del desarrollo territorial, Serie Gestión Pública núm. 13 de la CePaL-ILPES, agosto, Santiago de Chile, 2001.

Krugman, P., Geografia y comercio, Barcelona, España, Antoni Bosch, 1992.

Krugman, P. y M. Obstfeld, Economia internacional: teoria y politica, MgGraw Hill, España, 1995.

Krugman, P., Desarrollo, geografía y teoría económica, Antoni Bosch, Barcelona, España, 1997.

Pinto, A., "Notas sobre estilos de desarrollo en América Latina", Revista de la CEPAL núm. 1, Santiago de Chile, 1976.

Plan Estatal de Desarrollo. Gobierno del Estado de Nayarit 2005-2011.

Presidencia de la República, Decreto presidencial del 18 de noviembre de 1970, Diario Oficial de los Estados Unidos Mexicanos, 1970. 
Plan Nacional de Desarrollo Urbano de Ordenamiento Territorial-PNUD-OT 2001-2006..

Ruiz, A., Los recursos naturales en los tratados de libre comercio con Estados Unidos, CEPAL, División de recursos naturales e infraestructura, 2005.

,"El proceso de privatizaciones en el Perú durante el periodo 19912002", Serie Gestión Pública núm. 22, ILPEs, Cepal, Santiago de Chile, 2002.

Secretaría de Turismo, Boletín informativo: "La costa nayarita, un imán para las inversiones privadas", viernes 19 de enero de 2007. 